\title{
Analysis Of Influence Of Tourism And Branding Perceptions On Purchase Decisions (Study conducted in Chinatown as Halal Gastronomy in the City of Bandung)
}

\author{
Evin Davinci Sagala, Caria Ningsih, Dewi Turgarini \\ Indonesia University of Education, Jl. Dr. Setiabudhi No. 229, Bandung 40154, Indonesia \\ *Corresponding Author. E-mail: evindavinci5@gmail.com (Evin Davinci Sagala)
}

\begin{tabular}{|l}
\hline ABSTRACT \\
The purpose of this study is to be able to determine the effect of tourist perceptions and \\
Branding on purchasing decisions in the Chinatown tourist destination in Bandung. The \\
independent variables in this study are perception and branding, while the dependent variable of \\
this study is the purchase decision. The research method used in this research is quantitative with \\
descriptive and verification categories. The population of this study was 38,000 visitors with a \\
sample of 270 respondents. The sampling technique used is nonprobability sampling with a \\
purposive method. The data analysis technique used is multiple linear regression with assistive \\
devicesSPSS 25.0 for Windows computer software. The results showed that perception and \\
branding had a positive and significant effect on purchasing decisions in Bandung's Chinatown \\
tourist destination, both partially and simultaneously. \\
Keywords: Branding; Chinatown; Purchasing Decisions; Perceptions. \\
\hline \hline First Received: April 2019 \\
Final Proof Received: Juni 2019 \\
Putsed: Mei 2019
\end{tabular}

\section{Introduction}

According to (Republic of Indonesia Law No. 10, 2009) tourists are people who carry out tourism activities and are supported by various facilities and services provided by the public, private developers, or learn about the uniqueness of the attractions visited in the interim.

According to Inskeep in (Turgarini and Pridia, 2016), several components are involved in developing tourism destinations, namely:

Tourist attractions, namely tourist activities referred to in all matters relating to the natural environment, the uniqueness of an area and other activities related to tourism activities that attract tourists to visit tourist objects.

Accommodation is various facilities such as hotels and so on relating to services to tourists who intend to make lodging during their tour.

Amenitis is a variety of tourist facilities and services in the planning of tourist areas. Facilities include travel operations, restaurants and various other eateries, shops selling handicrafts, souvenirs, specialty shops, grocery stores, banks, money changers, personal services (such as beauty salons), treatment facilities, health facilities, public security facilities 
(including offices police and firefighters), and travel facilities for entry and exit (such as customs and immigration) and others are part of the facilities available on a tour.

Transportation is including access to transport to tourist areas and from tourist areas. Internal transportation that connects the main attractions of the tourist area and the development of the surrounding area, including all types of facilities and services related to land, water and air.

Infrastructure is the provision of clean water, electricity, drainage, sewerage and telecommunications.

Bandung, which cannot be separated by a variety of gastronomic offered to domestic and foreign tourists make Bandung became a priority with tourists, many of its restaurants offering typical characteristics and uniqueness of each individual with the brand are diverse and inviting attention. This condition makes many tourists who come to the city of Bandung and want to explore the gastronomic tourism including Chinatown as a halal gastronomic tour in the city of Bandung. Chinatown was inaugurated by Mr. Ridwan Kamil on Sunday, August 20, 2017, with the address of Chinatown being Jalan Klaten No. 41 Ciroyom, Andir, Bandung City, West Java. The opening ceremony conducted by Mr. Ridwan Kamil who previously served as the Mayor of Bandung at that time gave the inauguration speech with a statement that Chinatown restaurants are all halal. Responding to this with the branding of restaurants and tourist attractions with elements of China, and containing Chinese concepts, it becomes a problem for tourists to visit Chinatown destinations by considering aspects of halal food that can be accepted by Muslim tourists. this can affect the perception of tourists, and the influence of brands on tourists' decision to make a purchase at a gastronomic destination in Chinatown. This makes the writer conduct research with consideration of the problems taken as purchasing decisions. Purchasing decisions made by tourists, especially Muslim tourists in Chinatown whether influenced by perceptions built by tourists and influenced by brands that contain concepts and culture from China. Purchasing decisions made by tourists can be judged by the theories put forth by experts as stated (Kotler and Keller, 2012) that consumers who will make purchasing decisions will go through several stages and the stages are related to several aspects such as:

a. Choice of products or services

The selection of this product will be made with a variety of considerations made by tourists through perception, understanding, excellence and benefits.

b. Popularity Selection

Each brand has its own differences, so tourists must decide which brand to buy. Tourists will choose a brand based on, interest in brand image, interest in brand, price match.

c. Channeling options

Consumers must be able to make a decision about which supplier to use. In this case tourists must make decisions about which way to do to find effective due to location factors, appropriate prices, various supplies (facilities), convenience for shopping, breadth of place and also the quality of service.

d. Choice of visit time

Purchasing decisions for tourists are usually made in the selection of the time of purchase or different visits, according to when the tourist attraction is needed. The visit selection process includes several things such as suitability to needs, perceived benefits, reasons for visiting.

e. Number of purchases

Tourists can make decisions about how much tourist attraction will be visited at a time. Purchases may be made more than once. In this case the company must prepare as many products as the tourists want.

\section{f. Payment Methods}

Methods of payment by visitors can be done in several ways, namely paying cash, checks, credit cards, debit cards, ATM cards, 
credit through financial institutions, and credit through stores.

Based on this, the writer wants to do research in Bandung with the Chinatown object as a gastronomic tour in Bandung, with the research title: "Analysis of the Influence of Tourist Perceptions and Branding on Purchasing Decisions in Chinatown as Halal Gastronomic Tourism in the City of Bandung" this is in order to answer the existence of a mainstream tourist perception and branding of the Purchasing decision in Bandung's Chinatown.

The Formulation of Problems in this Research are:

a. What is the effect of perception on tourist purchasing decisions in Chinatown as halal gastronomic tourism in the city of Bandung?

b. How does the influence of branding on tourist purchasing decisions in Chinatown as halal gastronomic tourism in the city of Bandung?

c. How does the perception of tourists and branding influence on purchasing decisions in Chinatown as halal gastronomic tourism in the city of Bandung?

The objectives of this study are:

a. Knowing the influence of tourist perceptions to determine purchasing decisions in Chinatown as halal gastronomic tourism in the city of Bandung.

b. Knowing the effect of branding on tourists' decision to make a purchase in Chinatown as a halal gastronomic tour in the city of Bandung.

c. Knowing the influence of tourist perceptions and branding on purchasing decisions in Chinatown as a halal gastronomic tour in the city of Bandung.

\section{Literature Review}

\subsection{Halal Gastronomy}

Through the source (MUI 2008), it is explained that the process of halal procedures in restaurants issued by the food, medicine and cosmetics assessment institutions of the Indonesian Ulema Council (MUI) are as follows:
a. Understand halal certification requirements and attend $\mathrm{SJH}$ training
b. Implement a halal guarantee system
c. Prepare halal certification documents
d. Register for halal certification
e. Monitoring pre audit and post payment
f. Conducting audits
g. Carry out post-audit monitoring
h. Obtain halal certification

\subsection{Components of the Gastronomy Model}

According to (Turgarini Dewi, 2018) Understanding gastronomy is not only focused on culinary arts or cooking methods (figure 2.1), but also on human behavior including choosing raw materials, then tasting, tasting, serving, cooking and experiencing experiences of consuming and searching, studying researching and writing about food and all matters relating to ethics, ethics and human nutrition of every nation and country (Soeroso, 2014, KBBI, 2018, Lithilt, 2015, Shenoy, 2005, Manolis, 2010, Santich, 2010, Pullphothong \& Sopha, 2013). Gastronomy is an art and science, even appreciation that is cross-ethnic, national, racial, group, religious, gender, and cultural by studying in detail food and drink to be used in various conditions and situations.

Food as the main source of gastronomy is everything that comes from sources of agricultural products, plantations, forestry, fisheries, livestock, water and water, whether processed or not processed, which are intended as food and drinks for human consumption, including food additives, food raw materials and other materials used in the process of preparing, processing and making food or drinks. Another dimension of gastronomy is the binding nature of food, food and the environment (be it physical, biological or cultural) (Turgarini Dewi, 2018). 


\subsection{Assimilation of Chinese and Indonesian Gastronomy}

The entry of several countries and ethnicities into the archipelago gave knowledge and new things to the indigenous people, especially in the culinary world, this is not far from the current culinary archipelago which is food or culinary traditions from foreign countries such as India, Arabia, Europe and China. The tradition of eating in marriages in the archipelago today that adopts a buffet system is an assimilation of eating traditions from European countries and the most familiar Nusantara culinary food products on our tongues are biryani rice which is originally from Arab countries, and many others. In this discussion will discuss the assimilation of the gastronomic archipelago with the Chinese. Archipelago food is also greatly influenced by the entry of ethnic Chinese in the archipelago, some foods that are assimilated from ethnic Chinese in the archipelago:

\subsubsection{Semarang Spring Rolls}

Lumpia in Mandarin is called chun Juan or lun pia, so Nusantara people call it lumpi. But not a few people know that spring rolls are a mixed flavor. Its history begins with a young Chinese man who wandered and sold in Semarang by selling spring rolls containing pork (pork) beef bamboo with salty tastes and met with Javanese women who sold the same but different contents of potatoes and shrimp, after both were married then spring rolls in innovation with stuffing chicken, shrimp and bamboo shoots and wrapped in spring roll skin, this is a new history created in the culinary world of the archipelago and named Lumpia Semarang.

\subsubsection{Fried rice}

This rice-based food was first introduced by ethnic Chinese in the year $4000 \mathrm{BC}$ in their country. It is said that the Chinese people do not like food that is already cold, so add seasoning to the rice to have more value, with a good taste eating fried rice is widespread and enter Indonesia, the entry of fried rice culinary in Indonesia began in the era of Nusantara's trade relations with Chinese.

\subsubsection{Meatball Noodles}

Noodle is a food that is very well known all over the world and added with meat balls in it so as to create a new culinary in Indonesia as meatballs. Meatballs are foods that are very popular with Indonesian people, but the meatballs turned out to be culinary from China that entered Indonesia and mingled with the Archipelago's food. The history of the meatballs began with a child in China in the 17th century who had a love for his mother and gave rise to creative ideas for making beef with round shapes, this is because the mother was not allowed to eat meat because of its tough texture considering the age of her mother who was old so arises creative ideas for making meatballs. Buda assimilation occurs in the archipelago by adopting meatballs and adding spices made from spices in the meatballs.

\subsubsection{Milk Pie}

Some typical foods of each region in Indonesia will be a reminder and become an area of attraction. Milk pie is a food that is very familiar and is a typical food in the area of Bali. These foods are sought after when returning home from Bali, but pei milk has a history of food assimilation from several countries. Countries that have contributed in the direction of Bali's milk pie are China and Peortrugis. Tengs Cha Chaan was the first person to introduce milk pie in 1940 that spread throughout the world under various names. Likewise the Portuguese milk pie name is Pastel de nata, these two foods were adopted and there was a gastronomic assimilation in Indonesia under the name milk pie. 


\subsection{Perception}

\subsubsection{Definition of Perception}

The formation of perception begins with observation through the process of seeing, hearing, touching, feeling, and accepting something that someone then selects, organizes, and interprets the information he receives into a meaningful picture. The occurrence of this observation is influenced by past experience and the attitude of someone from an individual. Usually this perception applies only to him and not to others. In addition, this perception does not last a lifetime, can change according to the development of experiences, changes, needs, and attitudes of a person, both male and female.

The factors that influence one's perception are the characteristics of the person perceived and situational factors. According to (Mifta, 2005), there are two factors that influence one's perception, namely:

a. Internal factors: Individual feelings, attitudes, and personalities, prejudices, desires, or hopes, attention (focus), learning processes, physical states, psychiatric disorders, values and needs as well as interests, and motivation.

b. External factors: family background, information obtained knowledge and needs around, intensity, size, and resistance, repetition of motion, new things and familiar.

\subsubsection{Perception Indicators}

According to (Walgito, 2002) perceptions have the following indicators:

a. Absorption of stimuli or objects from outside the individual. The stimulation or object can be received by the five senses, both vision, hearing, touch, smell, and taste individually or together. From the results of the absorption will get a picture, response or impression in the brain. The picture can be single or distance, depending on the object of perception observed.

b. Understanding, after the image or impression, then the picture is organized, classified, compared, interpreted, so that understanding and understanding are formed. The process of understanding is very unique and fast. The meaning that is formed depends also on the old picture that has existed before the individual.

c. Assessment and evaluation, after the formation of understanding or understanding, there is an assessment of the individual. Individuals will compare the understanding and new understanding that is obtained with the criteria or norms that are subjectively owned by individuals. Individual valuations vary even if the objects are the same. Therefore perception is individual.

\subsection{Branding}

According to (Kotler and Armstrong, 2012) revealed that the brand is a communication strategy to enter the consumer window so that the product contains a certain meaning. Brand positioning is a way to place itself in the eyes of target consumers viewed from excellence. Brand is a part of brand identity and value proposition that is actively communicated to the target guests and shows its superiority over competing brands (AB Ssanto and Hilmawan, 2004) .

Brands that are created and designed must always be monitored with a variety of approaches, because of what competitors do will affect the configuration of the company and affect the brand that we have built. The following indicators of the brand according to (AB Ssanto and Hilmawan, 2004):

a. Value, focused on the benefits received by customers. The essence of value is what is received by the target market from the company's brand position.

b. Uniqueness, the core of uniqueness is to bring something that is not owned by other competitors so that the company's brand position offers a different offer than competitors. 
c. Credibility, shows how much credibility the company in the eyes of consumers.

d. Sustainability, the maxim of sustainability is to maximize the time span of time in which it occupies a position in the competition.

Conformity is such as conformity between brand position and company.

\subsection{Relationship Between Variables $X$ and Y}

Purchases made by consumers will have considerations. The purchase is caused by the occurrence of an objective stimulus, evaluation and evaluation (Perception) or because of an emotional impulse that encourages acting to make a purchase decision, and the purchase decision will be influenced by the psychological condition of the consumer and the brand that will be decided to be purchased.

Based on the theory put forward by (Kotler and Armstrong, 2012) about the decision making process, namely:

a. Stages of recognition of needs, introduction of needs are the first stage in the decision process, where consumers recognize problems or needs. The first need is stimulated by stimuli.

b. Information search is the consumer gets information from various sources including personal sources and commercial sources.

c. Evaluation of alternatives is that consumers evaluate alternatives to the selection of other brands that differ among the choices available.

d. Purchase decisions, are purchasing decisions for the brand that is considered the best chosen. There are two factors that underlie this, the behavior of other buyers and unexpected situation factors.

e. Post-purchase behavior, is the decision stage in which consumers take further decisions, they will feel satisfied or dissatisfied with a brand that they bought, then they will measure it through the post-purchase behavior stage. The process that occurs in making purchasing decisions has a very close relationship with perception, can be seen through the stages that are passed in the process of purchasing decision making is part of the indicators of perception itself, namely stimulation, understanding, and evaluation or evaluation according to (Walgito, 2002) .

Branding is a measuring tool used by consumers to make purchasing decisions. Branding is also a perception built by consumers in the form of a company's brand position. Branding will have an impression and perception that is in the minds of consumers when it will be considered in making a purchase decision. The creation of an impression is one of the basic characteristics in a modern marketing orientation, namely by giving more attention and a strong brand. Through the brand will lead to purchasing decisions by consumers because of an understanding that arises, with this it will be a consideration for consumers. Decision making will pay attention to this, where the brand will influence consumer purchasing decisions.

\section{Materials and Methods}

\subsection{Research Objects}

The object of research is a value or nature of other people, attributes, an activity that has certain variations that are determined by researchers then to be studied and drawn conclusions (Sugiyono, 2012) . The object variables in this study are divided into two parts: independent or often called independent and dependent variable or often called dependent. The independent variable is also called the influencing variable so that the dependent variable arises. The variables that I use in this study are:

a. Independent variable, namely tourist perception and branding (X).

b. The dependent variable, i.e. the purchasing decision (Y).

The research object of the two 
variables above is very important in this research to obtain data to be tested in a problem about the perception of tourists and Branding in Bandung's Chinatown. Research subjects to determine the perceptions of tourists and the influence of Branding are Chinatown destination visitors, especially Muslim visitors. In this study the authors will document and search for data by distributing questionnaires to find out how visitors' perceptions and the influence of branding in deciding purchases in Bandung's Chinatown.

\subsection{Research Methods}

The methodology is a theoretical framework used to analyze, work on and overcome the problems faced. Thus the research methodology is a scientific method and procedure applied to carry out research. Determine research variables, determine the study population, and determine the number of samples and samples to be studied, collect data and compile them into written reports.

This research uses quantitative research methods. According to (Sugiyono, 2010), quantitative research methods can be interpreted as research methods based on the positivism philosophy, used to examine specific samples or populations. Sampling techniques in research in general are generally carried out randomly, collecting data using research instruments, analyzing quantitative or statistical data. This study will clearly illustrate the relationship between the independent variable and the dependent variable, as well as test the truth of the hypothesis that has been prepared by the researcher. The research to be tested is regarding perceptions and branding of purchasing decisions in Bandung's Chinatown.

\subsection{Populations and Samples}

\subsubsection{Population}

Population can be interpreted as a generalization area consisting of: objects / subjects that have certain quantities and characteristics applied by researchers to be studied and then drawn conclusions (Sugiyono, 2007). According to (Riduan and Akon, 2010), the population is the whole of the characteristics or units of measurement results that are the object of research conducted or populations that are objects or subjects that are different in the region and meet certain conditions relating to the problem under study in the study. According to (Sujarweni V. Wiratna, 2014), the population is the total amount to be carried out by research consisting of objects or subjects that have certain characteristics and qualities determined by the researcher to be carried out research and then drawn conclusions. The population used for this research is visitors or tourists who Purchase to Bandung's Chinatown as many as 38,000 people each month.

\subsubsection{Sample}

Samples are part of the population. According to (Sugiyono, 2007), the sample is a portion of the number and characteristics possessed by the population to be examined which is determined by the researcher. Large population factors, the researchers will conduct a sample system. The results of processing the data examined from the sample are applied to the entire population. Therefore samples taken from the population must be used to represent that population.

The sample is part of a number of characteristics possessed by the population used for research. The conclusions obtained from the sample were applied to all populations in the study (Sujarweni V. Wiratna, 2014). The sample to be taken in this study uses a nonprobability sampling technique (a technique with non-random sampling). Mechanical nonprobability sampling is a sampling technique that is done by giving equal opportunity for each element or member of the population to be studied untukk been researcher in the sample to be studied. This nonprobability sampling technique includes quota sampling, 
saturated sample, snowball sampling, purposive sampling, and accidental sampling (Sugiyono, 2012).

This study uses purposive sampling which is a technique for taking respondents according to the characteristics determined by researchers with certain considerations and criteria. These study populations that will be used are visitors and consumers of the Bandung City Chinatown, and the determination for sampling so the authors use the formula Isaac and Michael, namely:

$$
S=\frac{\lambda^{2} N P(1-P)}{d^{2}(N-1)+\lambda^{2} P(1-P)}
$$

Then the obtained number of samples used is 270 visitors.

\subsection{Data Sources}

This study uses court lady sources obtained from research subjects. According to (Sugiyono, 2012), data sources in the study consisted of two sources, namely primary data sources and secondary data sources. Primary data is data directly obtained from the manager of the research site through statements given by the manager and directly given to the data collector. This statement was given directly by the manager of Chinatown with data collection methods in the form of observation, interviews, surveys and questionnaires.

Secondary data is a source that does not directly provide data to data collectors, for example secondary data is through other people or through documents. Secondary data obtained from this study through data library and literature relating to the problem under study.

\subsection{Data Collection Techniques}

Data collection is the activity of recording and taking data on events or things and information that is part or all of the elements of the population that will support or support research. Data collection can be done in various settings, various sources and various ways.
The data collection technique used is quantitative which is directly related to visitors and Chinatown processors who are connected with tourists' perceptions and branding towards Chinatown. To collect data in this study, the researchers used the following data collection techniques:

\subsubsection{Observation / survey}

Complex process is a process that is collected from various biological and psychological processes. Observations made by the author of Chinatown visitors and Chinatown processors. This observation aims to get information about Chinatown.

\subsubsection{Questionnaire}

The questionnaire is a data collection technique that is done by giving a set of statements and written questions to respondents to be answered and is also a technique for efficient data collection if the researcher knows with certainty the variables to be measured and knows what can be expected (Sugiyono, 2009) .

\subsection{Literature Study}

The author conducted a literature study of several sources of theory that have proven their truth. Sources can be in the form of books, journals, as well as previous scientific works that have conducted research.

\subsection{Test Validity and Reliability}

The instrument of the research can be said to be valid if it is able to measure what is desired and can reveal the data of the variables accurately and precisely according to (Wardianta, 2006), so that the writer can obtain information in accordance with the objectives and design of the study and can take measurements correctly, the research need to determine the measurement tools to be used in data collection in order to obtain quality data.

$$
\begin{aligned}
& r=\frac{n \sum X Y-\left(\sum X\right)\left(\sum Y\right)}{\sqrt{\left[n \sum X^{2}-\left(\sum X^{2}\right)\right]\left[n \sum y^{2}-\left(\sum y\right)^{2}\right]}} \\
& \text { Reliability according to (Arikunto, }
\end{aligned}
$$


2009), is an instrument that is trusted enough to be used as a data collection tool because the instrument is already good. Every good measurement will produce consistent measurements as well. Reliability testing in this study will use the reliability analysis method in the SPSS 25 program. To determine whether a statement or question in an instrument is valid or not, it must comply with the following criteria:

a. If $\mathrm{r}$ arithmetic> $\mathrm{r}$ table then the instrument is declared valid.

b. If $r$ arithmetic $<r$ table then the instrument is declared invalid.

c. Based on the number of questionnaires with a significant level of $5 \%$ and degrees of freedom $n-2(30-2=28), r$ tables were obtained for 0.374 .

An instrument is said to be reliable (reliable) means an instrument that is used several times to measure the same object, will produce the same data (Sugiyono, 2011). According to (Sujarweni and Endrayanto, 2012), reliability is a measure of the stability and consistency of respondents in answering matters related to the constructs of questions which are dimensions of a variable and are arranged in the form of questionnaires. The reliability test can be done together with all questions. With the formula:

$$
a=\left(\frac{k}{k-1}\right)\left(1-\frac{\sum \sigma_{b}^{2}}{\sigma_{t}^{2}}\right)
$$

The tested variable was declared reliable because Cronbach's alpha was more than the minimum standard of 0.60 and also the level of reliability was reliable.

\subsection{Normality Test}

Normality test aims to determine the independent variables and the dependent variable in the regression model has a normal distribution. One way to find out is by analyzing the hierogram graph and the P-plot graph comparing the observational data with a near normal distribution (Ghozali, 2011). Normality test can be known through the average value of residuals approaching 0 (zero) and the value of variance approaching 1 (one) on the histogram and marked with a histogram pattern also forms a bell, but it can also be known through the pattern of data spread (points) on the diagonal axis from the normal P-Plot chart. If the distribution pattern of the data is around the diagonal line and in the direction of the normal diagonal graph plot-plot, then the regression meets the assumption of normality.

\subsection{Multiple Linear Regression}

According to (Sudrajad and Suwaji, 2018), states that multiple linear regression analysis is a linear relationship between two or more independent variables with the dependent variable, or often interpreted as the relationship between two or more independent variables $(\mathrm{X} 1, \mathrm{X} 2, \ldots \mathrm{Xn})$ with the dependent variable (Y). This analysis is to determine the direction of the independent variable with the dependent variable positively or negatively related and to predict the value of the independent variable to increase or decrease.

\subsection{Test $\mathrm{T}$}

T test is used to determine whether the independent variables individually have a significant effect on the dependent variable. Individual independent variables are said to have a value (sig) smaller than the significant level $(\alpha)$ according to Sugiono in (Zulfikar 2012). Here's how to calculate a simple regression analysis ( $\mathrm{t}$ test):

$$
\mathrm{t}=\frac{\sqrt[7]{n-2}}{\sqrt{1-r^{2}}}
$$

T-counts are then compared with t-tables with a degree of error of 5\% ( ) with the criteria rejected if $\mathrm{t}$ - counts - $\mathrm{t}$-tables $(1$ $-\alpha / 2, n-2)$ or t-counts t-tables $(1-\alpha / 2$, $\mathrm{n}-2)$.

\subsection{Test $\mathrm{F}$}

According to (Alfianika, 2016) said that the test $\mathrm{f}$ aims to see whether the two samples have a homogeneous variance or 
not. To test $f$ so that the variance of each data is known, the following formula is used:

$$
F=\frac{s_{1}^{2}}{s_{2}^{2}}
$$

If $\mathrm{F}$ has been set, then it is compared with $\mathrm{F}$ contained in the $\mathrm{F}$ distribution with a significant level of $5 \%$ and $\mathrm{dk}$ numerator $=$ -1 , dk denominator -1 . When price < means the data group has homogeneous variance. Conversely, if > means the two groups of data have non-homogeneous variance.

\subsection{Correlation Test}

According to (Kurniawan and Budi, 2016) said that the correlation analysis aims to find out whether there is a relationship between variables and the closeness of the relationship. The relationship between variables can be positive or negative, and 0 (zero) if there is no relationship at all. The strength of the relationship between variables can be expressed by the magnitude of the correlation coefficient (r) in the linear function. Linear correlation lies between -1 and $1\left(\begin{array}{lll}-1 & \mathrm{r} & 1\end{array}\right)$. The correlation coefficient between the two variables if it has a positive $r$ value is unidirectional, and vice versa if the $r$ value is negative then it is the opposite direction.

\section{Results and Discussion}

\subsection{Overview of Object}

Bandung's Chinatown is a new destination that opened in mid 2017, precisely on Sunday (08/20/2017) which was inaugurated by the Bandung Culture and Tourism Office (DISBUDPAR) and Bandung mayor Ridwan Kamil, accompanied by his wife, Atalia Ridwan Kamil inaugurated Chinatown Bandung on Jalan Kelenteng No. 41 Bandung. The downtown area of Bandung is tidying up with the presence of the Chinese-style concept of Bandung. Chinatown visitors can enjoy the atmosphere of a unique Chinese village style, regarding this concept $\mathrm{Mr}$. Ridwan Kamil said this is a manifestation of the diversity that has been the hallmark of Bandung, Mr. Ridwan Kamil said this Chinatown reinforces the existence of the city of Bandung that really appreciates differences. "Diversity is manifested in religious tolerance, daily social activities, and in economic activities. This is a manifestation of the diversity of identities in the economy".

Chinatown area, currently has 80 Tenants who are from Bandung SMEs. The contents vary from culinary, fashion, to handicraft. In Chinatown there is also a special museum, there is a room that reads "Bandung Chinatown Museum". Visitors can see a variety of antique Chinese furniture. In addition, there is an infographic that tells the history of the Chinese in Bandung. Then, visitors can enjoy the culinary sambal hang out or take pictures because there are many interesting spots that can be made as a unique selfie setting. The colorful buildings of various lanterns hanging over the road can be a spot to take photos. Seeing the history of Chinatown is a building owned by the PERMABA Foundation (Bandung Society Association). Right behind the oldest temple complex in Bandung, Vihara Satya Budhi. Since the formation of this tourist area in collaboration with the social community of Bandung (PERMABA).

Chinatown combines commercial and cultural elements. Residents who visit not only can enjoy Bandung products, but also get to know more closely with Chinese culture. Chinatown tourism operating hours for Monday-Friday open at 09:00 to 21:00 WIB, Saturdays from 10:00 to 22:00 WIB and Sundays or national holidays from 10:00 to 21:00 WIB. As for the entry ticket Monday to Sunday is Rp. 30,000. In addition to culinary and hanging out, visitors can also shop for a variety of knick knacks or souvenirs as well as various antiques. The concept of open culinary tourism, visitors can enjoy the atmosphere of Chinatown in the chairs provided, as for the variety of foods and drinks offered halal 
because it does not contain pork and pork oil (Chinatown, 2019).

4.2. Organizational Structure

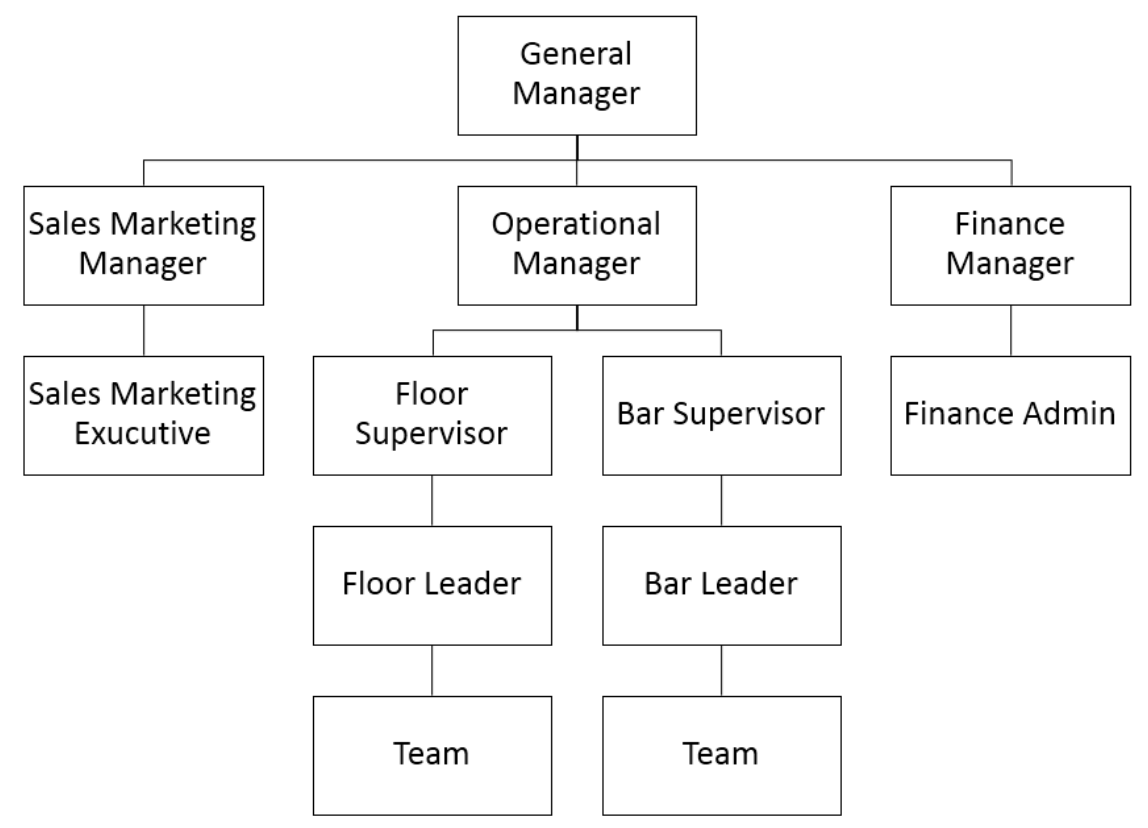

Figure 1. Organizational Stucture of Chinatown

Based on Figure 1 according to (Chinatown, 2019), the organizational structure of Chinatown Bandung has 1 General Manager is the person who acts as the overall responsible for Chinatown, has the task of leading, setting policies, and formulating strategies for Chinatown. Manager division which consists of 3 parts, namely marketing, operational, financial has the task of carrying out policies from the main leadership according to the division and reports the work to the general manager, S\&M executive, Supervisor consisting of 2 divisions, and financial admin has the task of controlling the occurrence of the company's work cycle in each division and report to the division manager. In the operational section there are 2 leaders, namely the leader floor and bar in the section that specifically handles operations in the form of food and drinks, is responsible for handling food and drinks and their quality, and reports to supervisors. The team in each section of the leader is the person who will work on operations in preparation, cooking, serving and service.

\subsection{Chinatown Vision and Mission}

The vision of Chinatown says (Chinatown, 2019), that with the growth of the tourism climate of the city of Bandung especially tourist destinations, it makes Chinatown wants to provide a means of cultural tourism that is easily accessible to the community. Because most of the tourist attractions (leisure) are in the area of North Bandung and Lembang, Chinatown creates a green space in the center of Bandung. In addition to a selfie tour / photo, Chinatown Bandung also presents a cultural history of the formation of Chinatown in the city of Bandung. There are also food tenants who sell all kinds of typical Chinese food to the archipelago cuisine. Uniquely, all foods and drinks in Chinatown Bandung do not contain pork and lard.

The Bandung Chinatown mission is based (Chinatown, 2019), which is to invite people to better understand that cultural differences are beautiful. The combination of Chinese and regional culture forms a new culture that is unique and interesting 


\subsection{Perception Variable (X1)}

The perception of Chinatown Bandung is in the category of good (quality) criteria with a percentage of $82.1 \%$. T test results showed that the perception variable had a significant influence on purchasing decisions at the Bandung Chinatown gastronomic tourist destination. That is because the stimulation of information given by Chinatown to potential visitors is positive and easy for consumers to accept, as well as understanding, Chinatown provides information that is easily understood and understood by potential visitors and the last is Chinatown is able to give an impression that good for consumers, giving rise to good judgment. Of the three things that are meant by indicators of perception that make perception variables provide a significant and positive influence.

\subsection{Variable Branding (X2)}

Branding in Chinatown gastronomic tourist destinations is included in the criteria of good (quality) with a percentage of $83.2 \%$. T test results indicate that branding has an influence on purchasing decisions in the Bandung Chinatown gastronomic tourist destination. This is due to the accumulation of several indicators that support branding such as uniqueness, credibility, sustainability, suitability, and what becomes a very strong person is the uniqueness offered by Chinatown Bandung by having the concept of halal gastronomy with Chinese nuances that makes consumers or visitors curious and get good results when you go directly to the destination Chinatown Bandung.

\subsection{Implementation of the effect of perception and branding on purchasing decisions}

Perception and branding which become independent variables in the research used to examine Chinatown is an accumulation of several indicators contained in it by having good criteria (quality). The results of the $\mathrm{F}$ test show that perception and branding have a significant influence on purchasing decisions by $61.4 \%$. So the stimulation, understanding, assessment, uniqueness, credibility, sustainability, conformity which are indicators of perception and branding have a significant influence on purchasing decisions in Chinatown Bandung.

Based on the description above, it can be seen that perception and branding in accordance with the results of correlation and determination analysis show that perception and branding have a positive effect. The most dominant aspect influencing purchasing decisions is branding because it has a $\mathrm{T}$ test result (Ttable) greater than perception. Based on the results of research to 270 respondents who visited the Chinatown Bandung gastronomic tourist destination was influenced by perception and branding by $61.4 \%$ and $38.6 \%$ were influenced by other factors not yet examined.

\section{Conclusions}

Based on the research and regression tests conducted on the effect of perception and branding on purchasing decisions in the Bandung Chinatown gastronomic tourist destination, the results of this study can be concluded in this study.

Perception has a significant and positive influence on purchasing decisions; this is indicated by the results of testing partially. Perception has three indicators such as stimulation, understanding, and judgment. The indicator of perception that has the highest value is valuation; this is because an interesting concept applied by Chinatown has good support and judgment because it has a unique value as an attraction. Understanding indicator is the lowest value on the perception variable, this is due to lack of clarity of information provided by the Chinatown in the promotion carried out so that consumers do not understand the concept of Chinatown.

Branding has a significant effect on 
purchasing decisions in Chinatown. The uniqueness indicator gets the highest score due to the uniqueness of the Chinatown concept, namely halal gastronomy with Chinese nuance and unique shape of the room with Chinese-style decoration on each side of the room such as restaurants, photo spots, relaxing places (parks) so that the indicator of uniqueness gets more appraisals from visitors. The indicator that gets the lowest score is the credibility and sustainability of this is due to the level of consumer confidence in halal products and always maintains a small halal food, the factor is the lack of information about halal food in Chinatown.

Perception and branding have a significant and positive effect on purchasing decisions in Bandung's Chinatown gastronomic tourist destination, this is evidenced by testing conducted by using simultaneous tests by researchers which shows that perception and branding have a large influence on purchasing decisions. In accordance with the results of tests conducted using the SPSS 25.0 application for it 's window .

\subsection{Suggestions}

Based on the results of research that has been carried out on perceptions and branding of purchasing decisions in the Bandung Chinatown gastronomic tourist destination, the authors propose suggestions in accordance with the research that has been done. Here are a few suggestions from the authors based on the research findings as follows:

a. Building perceptions and branding that has contributed greatly to purchasing decisions in Bandung's Chinatown gastronomic tourist destination, but among the research variables are the perceptions that have the lowest values. Management from Chinatown should be able to provide better information to consumers and easily understood in order to cause good perception to Chinatown, Bandung. b. Research variables regarding perception and branding have indicators in each of its variables. Perception has an indicator of understanding that has the lowest value, so the suggestion from the author to improve the promotion system and disseminate information about Chinatown is better with brief, concise and clear information. The indicator of the branding that gets the lowest score is credibility and sustainability, this is because consumers lack confidence in the halalness of the product, therefore Chinatown should provide more information that Chinatown sells halal food through social media or attributes installed in the Chinatown building and issue certifications lawful.

c. The decision to purchase the popularity dimension gained a high value. It proves that Bandung's Chinatown is known in the community. Selection of the number of purchases that get the smallest value. This requires attention from the management of Chinatown Bandung in order to provide sufficient space to sell food and it is best that any shortage of food sales be corrected by management to encourage the number of revenue visits.

d. The results of this study, the implementation of building perceptions and branding has an influence on purchasing decisions in Chinatown Bandung, therefore overall the company must further develop and make a study to strengthen the perception and branding of Chinatown one of them by providing good information and multiplying places, design, attraction, unique food as one of the marketing strategies in the minds of consumers of Chinatown Bandung, that Chinatown is a unique place that has a concept of halal gastronomy with a Chinese feel.

e. As a material consideration for conducting further research in terms of 
improving purchasing decisions and business development in Bandung's Chinatown, it is recommended to conduct research relating to business development strategies for developing Bandung's gastronomic tourist destination.

\section{References}

Mifta, T. (2005). Behavior of Basic Concepts and Its Applications . Jakarta: PT Raja Grafindo Persada.

Ningsih, C. (2016). The Synergy of Tourism-Based Creative Industries with the National Industry Development Strategy Towards Globalization

Soekadijo, R. (2000). Anatomy of Tourism (Understanding Tourism as "Systemic Linkage") . Jakarta: PT Gramedia Pustaka Utama.

Sugiyono (2007). Statistics for Research . Bandung: Alfabeta.

Sugiyono (2009). Qualitative Quantitative Research Methods and R\&D . Bandung: Alfabeta.

Sugiyono (2010). Quantitative Research Methods . Bandung: Alfabeta.

Sugiyono (2011). Combination Research Method . Bandung: Alfabeta.

Sugiyono (2012). Understanding Qualitative Research . Bandung:
Alfabeta.

Sujarweni V. Wiratna. (2014). Research Methodology (1st ed.). Yogyakarta.

Sunaryo (2004). Psychology for Nursing . Jakarta: EGC.

Suwantoro, G. (2004). Tourism Basics . Jogyakarta: Andi Offset.

Walgito, B. (2002). Introduction to General Psychology . Yogyakarta: Andi Offset

AB Susanto and Hilmawan. (2004). Power

Branding: Build superior brands and supporting organizations . Jakarta.

Kotler and Armstrong. (2012). The Principales of Marketing . New JERSEY: Pearson / Prentice hall.

Kotler and Keller. (2012). Marketing Management . New JERSEY: Pearson Education, Inc.

Mizan Pulika Jakarta tkins, P. \& Friedman, R. (2005). Molecular Quantum Mechanics (4th ed.). New York: Oxford University Press Inc.

Rai Utama \& I Gusti Bagus. (2017). Tourism Marketing . Yogyakarta: Andi Offset

Riduan and Akon. (2010). Formulas and Data in Statistical Applications. Bandung: Alfabeta

Republic of Indonesia Law No. 10. Regarding Tourism ., (2009).

Republic of Indonesia Law No. 9. Tourism ., (1990) 